\title{
'Gangrenous Meckel's Diverticulum with Axial Torsion Presenting As an Abdominal Lump
}

\author{
Dr. Amitabh Kumar*,Dr. Saurabh Y. Bokade**
}

\begin{abstract}
Keywords Meckel's diverticulum, vitellointestinal duct, torsion, obstruction.
\end{abstract}
\section{Introduction}

Meckel's diverticulum is a developmental anomaly due to patent vitellointestinal duct. Complications of meckel's diverticulum are bleeding, intestinal obstruction or torsion being one of the rare complications. Diagnosis is mostly incidental.The use of Tc $99-\mathrm{m}$ pertechnetate or Tc $99-\mathrm{m}$ sulfur colloid is primarily for investigating gastrointestinal bleeding and may not be applicable in a case of intestinal obstruction[1].. Treatment is mainly surgery.

\section{Case Report}

Here we report a case of 35 years old gentleman admitted to the Tata Main Hospital with the chief complaints of diffuse pain abdomen and vomiting multiple episodes since 3 days, abdominal distention since 3 days and not passing stools since 2 days. General examination was normal. Per abdomen examination suggested diffuse guarding and tenderness in the right iliac fossa. Vague lump palpated in right iliac fossa which was considered as an appendicular lump . Digital rectal examination was done suggestive of ballooning of rectum. Urgent $\mathrm{x}$ ray revealed multiple air fluid levels. Ultrasound scan suggested fatty liver with bulky pancreas. Patient was posted for exploratory laparotomy after failed conservative trial for 48 hours. Initially patient was given conservative trial for 48 hours. But patient condition does not showed signs of improvement, so decision was taken for laparotomy. On exploring the abdomen a lump was found in the right iliac fossa. On exploring the lump a peritoneal band was broken by finger dissection, gangrenous meckels diverticulum was found about 50 $\mathrm{cm}$ from the ileocecal junction with axial torsion and cecum was densely adhered (Fig.1). Appendix was autolysed. Segmental resection followed by anastomosis done in two layers. Post operative period was uneventful and patient was discharged on post operative day 6 .

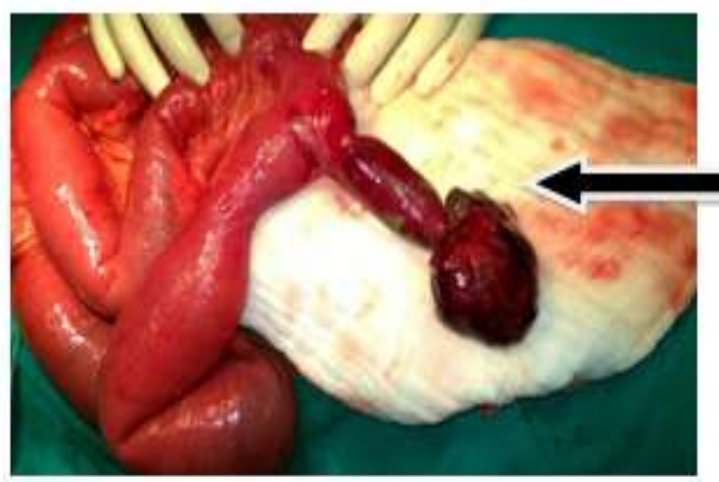

GANGRENOUS MECKELS

DIVERTICULUM WTTH

AXIAL TORSON

Fig. 1

\section{Discussion}

Meckel's diverticlum is named after John Meckel (1812). It is due to persistent of patent vitellointestinal duct. Male to female ratio is $2: 1-5: 1$. It is mostly an incidental finding. Some people may proceed with diagnostic laparoscopy[2].Generally it does not require any surgical management unless complicated. In all age groups, life time risk of developing complications requiring surgery is 4-6\%. Complications are bleeding > obstruction > torsion, with torsion being the rare complications. Risk factors for torsion are length and diameter of the diverticulum. An elongated MD with a narrowed neck is far more likely to result in torsion. In our patient, the diverticulum was $15 \mathrm{~cm}$ long and $4 \mathrm{~cm}$ wide, perhaps predisposing it for torsion. Treatment is resection of the gangrenous part followed by anastomosis if complicated. 


\section{Conclusion}

Meckel's diverticulum does not require surgical intervention unless complicated. Surgery is the mainstay of treatment for gangrenous meckel's diverticulum. Complications are few, torsion being the rare of those and torsion presenting as an abdominal lump is rareset.

\section{Reference}

[1]. Ruiz VA, Camacho LA, Díaz DC. Giant Meckel's diverticula with necrosis due to axial torsion. Rev Col Gastroenterol. 2010;25:398-400.

[2]. Ding Y, Zhou Y, Ji Z, Zhang J, Wang Q. Laparoscopic management of perforated Meckel's diverticulum in adults. Int J Med Sci. 2012;9:243-7. [PMC free article] [PubMed] diagnostic lap

[3]. Cartanese C, Petitti T, Marinelli E, Pignatelli A, Martignetti D, Zuccarino M, et al. Intestinal obstruction caused by torsed gangrenous Meckel's diverticulum encircling terminal ileum. World J Gastrointest Surg. 2011;3:106-9. [PMC free article] [PubMed]

[4]. Kiyak G, Ergul E, Sarikaya SM, Kusdemir A. Axial torsion and gangrene of a giant Meckel's diverticulum mimicking acute appendicitis. J Pak Med Assoc. 2009;59:408-9. [PubMed]

[5]. C. Limas, K. Seretis, C. Soultanidis, and S. Anagnostoulis, "Axial torsion and gangrene of a giant Meckel's diverticulum," Journal of Gastrointestinal and Liver Diseases, vol. 15, no. 1, pp. 67-68, 2006

[6]. *Associate Specialist, Gen. Surgery, TMH, Jamshedpur.

[7]. **DNB Gen. Surgery, TMH, Jamshedpur. 